\title{
Turner's Trinity
}

Turner is famous as a master of the use of primary colours to depict light in painting. What is less well known is that he was also a student of the science behind that art.

\section{Martin Kemp}

W

hen J. M. W. Turner was asked to explain his pair of paintings exhibited at the Royal Academy in 1843, Shade and Darkness - the Evening of the Deluge and Light and Colour (Goethe's Theory) - the Morning After the Deluge, he tersely responded, "Red, blue and yellow". This triad comprised painters' traditional 'primaries', from which (in theory) all other colours could be mixed.

\section{Looking at the swirling chaos of colour in Turner's vision of the Deluge's aftermath, it is difficult to believe that it is founded on scientific ideas, yet he cites "Goethe's Theory" - the anti- Newtonian doctrines expounded in Goethe's Farbenlehre in 1810.}

Goethe, although on the eccentric fringe of science, was far from alone at that time in reviving the three-colour theory in the face of Newton's apparently triumphant doctrine of seven unrefrangible hues.

For example, Sir David Brewster, the Scottish scientist and biographer of Newton, polemically advocated what he called the "Trinity" of colours. Relying upon observations of the decomposition of light by absorption through coloured filters, Brewster argued that white light was produced by three overlapping spectrums of red, yellow and blue.

Although Turner, who met Brewster, realized that actual mixtures of "aerial" colours (additive mixing of coloured lights) and "material" colours (subtractive mixtures of pigments) produced quite different results, he welcomed the idea that there was a direct correspondence of hue between the primaries for lights and pigments.

Given Turner's status as the supreme exponent of Romanticism in British art, his avid interest in scientific theory comes as something of a surprise. He devoted long

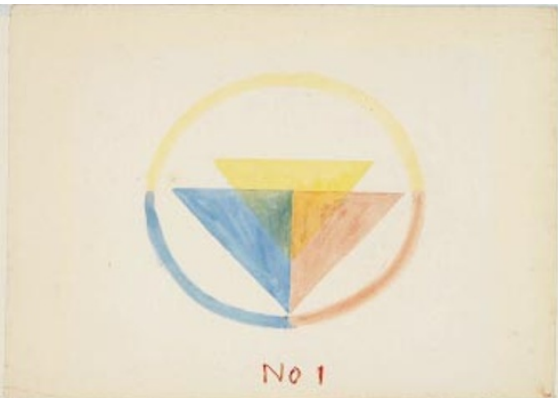

Colour Circle No. 1: diagram of the "aerial colours" from Turner's lectures (Tate Gallery, London).

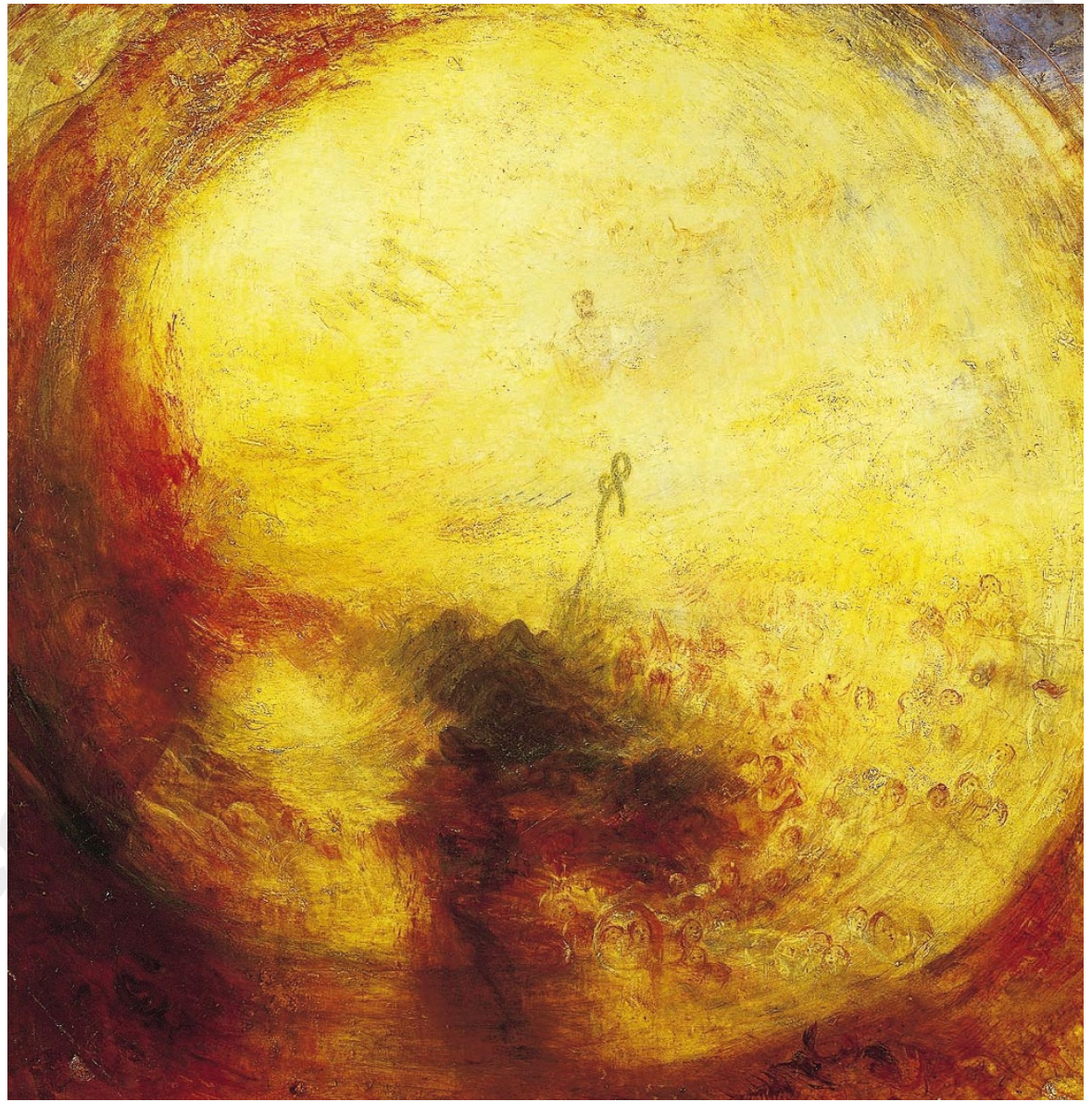

J. M. W. Turner's Light and Colour (Goethe's Theory) — The Morning After the Deluge, 1843 (Tate Gallery, London).

hours to the preparations for his lectures as professor of perspective at the academy, where he introduced his audience to Euclidean geometry and the complex issues surrounding the strengths and fallacies of conventional perspective. He was conscious that each portion of space depicted in perspective was a fragment of an infinite whole, and that our eyes embrace an orbital sweep of concave space, dynamically evoked in the Goethe canvases.

Scientific insight, for Turner, was never a matter of 'restrictive rule', but provided access to the awesome powers of nature. He was fascinated by the magnetizing properties of light, and by the action of sunlight on silver salts as exploited to such effect by the pioneers of photography.

Turner did not swallow Goethe's theory whole. "Poor Dame Nature" he wrote in one of his annotations to his copy of the 1840 translation of Farbenlehre, when he felt that
Goethe was downgrading nature's supreme powers. But he was attracted to the way the German set his two "polar" colours, yellow and blue, in concert with paired forces of nature: plus and minus; action and negotiation; force and weakness; warmth and coldness; proximity and distance; repulsion and attraction; acids and alkalis, and so on.

In Turner's pair of paintings, the dark, hollow, fractured vortex of the looming Deluge, dominated by negative hues, is set against the spherical whirl of warmly radiant hope. Yet, as the poetic fragment Turner appended to Morning After warns, "Hope's harbinger" - in the guise of the multicoloured bubble studied by Goethe - is "as ephemeral as the summer fly, Which rises, flits, expands and dies".

For Turner, scientific awe and poetic melancholy coexisted within a single mental spectrum.

Martin Kemp is in the Department of the History of Art, University of Oxford, 35 Beaumont Street, Oxford OX12PG, UK. 